\title{
UMA RESPONSABILIDADE PELO QUE NÃO FIZEMOS? A MEMÓRIA COMO FUNDAMENTO DA RESPONSABILIDADE HISTÓRICA EM WALTER BENJAMIN E REYES MATE
}

\author{
A responsibility for what haven't done? Memory as the \\ foundation of historical responsibility in Walter Benjamin \\ and Reyes Mate
}

\section{Diogo Justino*}

\begin{abstract}
RESUMO
Este artigo pretende explorar as relações entre memória e história a partir das experiências de violência e injustiça, pensando a centralidade das vítimas para uma teoria da justiça. Abordaremos os vínculos entre presente e passado em Walter Benjamin e a noção de memória da injustiça como fundamento de uma ideia de responsabilidade histórica em Reyes Mate; ou seja, uma responsabilidade que extrapola os limites da responsabilidade individual-liberal-jurídica. Pensar o presente a partir do passado, sobretudo a partir das experiencias de injustiça, seria pensar também as responsabilidades que as gerações do futuro possuem com relação às gerações do passado.
\end{abstract}

Palavras-chave: responsabilidade; memória; história.

\begin{abstract}
This article aims to explore the relationship between memory and history from the experiences of violence and injustice, thinking about the centrality of victims towards a theory of justice. We will address the links between present and past in Walter Benjamin and the notion of
\end{abstract}

\footnotetext{
* Mestre e Doutor em Teoria e Filosofia do Direito (UERJ), com período sanduíche no Instituto de Filosofia do CSIC (Consejo Superior de Investigaciones Científicas - España), coordenador do GT Direitos, memória e Justiça de Transição do IPDMS (Instituto de pesquisa, direitos e movimentos sociais) e membro do LabCap (Laboratório de críticas e alternativas à prisão). E-mail: diogopjs@ gmail.com
} 
memory of injustice as the foundation of an idea of historical responsibility in Reyes Mate; that is, a responsibility that goes beyond the limits of individual-liberal-legal responsibility. Thinking the present through the past, especially from experiences of injustice, would also mean to think about the responsibilities that future generations have regarding past generations.

Keywords: responsibility; memory; history.

\section{Introdução}

O homem atentou contra o homem e tem que prestar contas disso. Não quero dizer que todo mundo seja culpável ou que todos sejamos vítimas e carrascos, mas que ninguém pode se desentender do sofrimento alheio porque a humanidade fez a experiência de que esse mal é uma injustiça causada pelo homem, $\mathrm{O}$ recordar do sofrimento que o homem inferiu ao outro homem coloca sobre os ombros de qualquer ser humano a carga da responsabilidade sem limites em face do mal no mundo. O novo é encarregar-se de todo mal causado pelo homem. - Reyes Mate

A história do Brasil é marcada por eventos de violência, repressão social, lutas e resistências - colonização, escravidão, guerras, genocídios, ditaduras. São eventos que deixam marcas na sociedade e nos formam enquanto nação. Lidar com essas marcas das injustiças do passado é fundamental para a compreensão e superação das injustiças do presente. São muitas as possibilidades de respostas sobre como lidar com um passado autoritário, que produz racismos, banalização da tortura, violência policial e outras formas de opressão no presente. Por exemplo, no âmbito dos acontecimentos da Ditadura militar brasileira, fala-se em justiça de transição, uma forma de organizar a passagem de um momento ditatorial para as democracias liberais. É central neste modelo a ideia de responsabilizações individuais daqueles que foram agentes do regime anterior. Neste caso, há uma complexa gama de responsabilidades, desde 
aqueles cidadãos comuns que apoiaram o golpe, as empresas que financiaram, os veículos de comunicação que deram suporte até os agentes que de fato praticaram crimes previstos pelo Direito. Esta complexa gama de responsabilidades não pode ser captada por uma sentença judicial. $\mathrm{O}$ mesmo pode ser dito de um caso de violência estatal recente, a chacina do Carandiru, onde o Tribunal de Justiça de São Paulo, até a presente data, se nega a apontar responsabilidades alegando dificuldades em individualizar as condutas dos policiais ${ }^{1}$. Evidentemente porque para o direito, os fatos devem ser imputados pessoalmente aos indivíduos e esta é uma garantia das democracias liberais. Neste caso, caberia perguntar sobre as responsabilidades dos agentes públicos que administravam o Estado de São Paulo à época e de parte da sociedade que legitima a atuação dos policiais.

Alguns regimes ou eventos desafiam as noções de responsabilidade individual. Poderíamos citar o caso do nazismo e do holocausto. Apesar de algumas pessoas terem sido responsabilizadas, sabemos que com o fim da segunda guerra mundial, um inusitado sentimento pairou sobre parcela da sociedade alemã: a culpa coletiva. Com a ideia de culpa coletiva, muitas vezes repetida, apresentava-se a sensação de que o mal do nazismo poderia ser atribuído a todos (com exceção das vítimas, obviamente). Os que mandaram, os que obedeceram, aqueles que não se rebelaram, que viveram a indiferença, os burocratas, e mesmo aqueles que, como lamentou Primo Levi (2004.p. 144), não haviam tido a coragem sutil de nos olhar nos olhos, de nos dar um pedaço de pão, de murmurar uma palavra humana - todos teriam contribuído de alguma forma com a máquina de destruição. Além disso, haveria também uma culpa dos descendentes pelo que fizeram seus ascendentes. Roberto Aramayo (1999, p. 27) narra o curioso caso de uma jovem alemã que viajou até Guernica para pedir desculpas pelo bombardeio que destruiu a cidade. Era filha de um dos aviadores. Similarmente, uma carta anônima de um africâner reconhecendo a culpa coletiva de sua comunidade pelo Apartheid foi lida na Comissão da verdade e Reconciliação da África do

1 A $4^{\text {a }}$ Câmara Criminal do Tribunal de Justiça do Estado de São Paulo anulou a decisão do Júri que havia condenado 73 policiais militares pelo massacre do Carandiru, onde 111 presos foram assassinados. Os desembargadores alegaram que não houve individualização das condutas dos réus policiais, que não ficou provado qual réu matou qual vítima. EL PAÍS. Justiça de São Paulo anula julgamentos de PMs pelo massacre do Carandiru. 29 de setembro de 2016. Disponível em <https://brasil.elpais.com/brasil/2016/09/27/politica/1475004354_366390.html>. Último acesso: 09 de setembro de 2019. 
Sul (GARAPON, 2004, p. 198-199). Como apontar responsabilidades (no sentido de imputar a alguém um dano) daqueles que apenas obedeciam às ordens, aos burocratas que não sujaram as mãos? Qual seria, por exemplo, o nível de responsabilidade dos maquinistas dos trens que levavam judeus para os campos? Era exigível que eles puxassem o freio? Era possível, por exemplo, distinguir apoiadores em muitas esferas; desde aqueles que executaram judeus nos campos até cidadãos comuns, que poderiam ser meros funcionários do Estado, ou comerciantes que se negavam a vender para judeus.

Este trabalho pretende se inserir no debate em torno da memória para abordar uma forma de responsabilidade que vai além da personificação, que muitas vezes isola o conflito, individualiza as opressões e ajuda pouco uma compreensão mais ampla e conjuntural. De que forma podemos ser responsáveis pelo passado? Poderíamos ser responsabilizados pelo que não fizemos? Essas questões importam quando falamos de continuidades, de heranças históricas, do passado comum que pode nos vincular a oprimidos e opressores, dependendo da posição que tomamos no presente. As políticas de memória devem lidar com essa dimensão da responsabilidade. A responsabilidade pelo que não fizemos. Uma mudança de olhar, para fora e além do ato. Essa abordagem pode apontar para responsabilidades históricas, para com as injustiças do passado; responsabilidades com o futuro, intergeracional e ambiental; responsabilidades coletivas, de solidariedade e não-individualista, responsabilidades pelas consequências da ação. Enfim, na ética e na filosofia muitos autores têm buscado respostas que atravessem o individualismo do conceito dominante de responsabilidade.

Este é o debate colocado aqui. A noção de responsabilidade é central no Direito, mas também na Ética e na Política. Para Reyes Mate (2011, p. 246), por exemplo, cada tempo possui uma construção ética que se move em torno de um eixo específico. Nos antigos, a virtude. Nos modernos, o dever. E, para nós, contemporâneos, a responsabilidade. Segundo Klaus Gunther (2009. p. 01), em cada época há palavras às quais se vincula mais intimamente o espírito objetivo de uma sociedade. Isso se percebe pelo uso frequente das mesmas e, especialmente, porque seu uso não recebe nenhuma objeção, nem ao menos a pergunta sobre seu significado - atualmente a palavra responsabilidade parece desempenhar esse papel. Responsabilidade fiscal, política, coletiva, social, individual, ambiental; crime de responsabilidade, responsabilidade ao dirigir, 
responsabilidade na academia etc. Muitos termos se agregam a essa ideia, oferecendo contornos diferentes e, por vezes, contraditórios.

Assim sendo, este trabalho buscará compreender a ideia de responsabilidade histórica. Para isso, iniciaremos abordando o tema da memória e sua importância para a compreensão da sociedade atual. Depois trabalharemos especificamente a noção de responsabilidade histórica, tomando como marco teórico Walter Benjamin, que propõe a vinculação entre os oprimidos e opressores do passado e do presente e Reyes Mate, que a partir disso tentará formular uma proposta de responsabilidade histórica.

\section{Lembrar ou esquecer?}

O debate sobre o tema da memória tem se alastrado pelo mundo e ganhado força na América Latina, assaltada por muitas ditaduras militares que deixaram um saldo imenso de violações de direitos humanos. No entanto, nem sempre foi assim. Para os antigos e medievais a memória era, em primeiro lugar, um sentimento pessoal e, em segundo lugar, uma categoria conservadora cultivada pelos defensores da tradição (MATE, 2008, p. 156). Isso explica, em certa medida, a resistência que a memória enfrentou em diversos campos do saber na Modernidade. A situação começou a mudar com as grandes guerras do século XX, sobretudo após a Segunda Guerra e o surgimento da reflexão em torno do dever de memória.

A ideia de um "direito à memória" ou à "verdade" é recente e ainda bastante controvertida. Memória e verdade costumeiramente aparecem em conjunto na linguagem da Justiça transicional, apesar de serem categorias diferentes. Os direitos relacionados ao tema normalmente estão mais diretamente ligados a categoria "verdade"; por exemplo, o direito ao acesso às informações escondidas do período da ditadura militar. Alguns autores afirmam a impossibilidade de um "direito à verdade", não cabendo ao Estado tutelar qualquer verdade, sendo que aceitar esta ideia seria acreditar na própria ideia tão problemática de verdade oficial, ou mesmo na ideia de uma verdade essencial (DIMOULIS, 2010. p. 101-104 e DIMOULIS \& SABADELL, 2011. p. 88.), quando muitas vezes os 
próprios militantes pró-memória divergem quanto aos fatos passados. Em contrapartida, outros pensadores dizem que o "direito à verdade" não se refere à imposição de uma narrativa única, mas que outras narrativas sejam possíveis; na prática, significaria a possibilidade de esclarecimento público sobre a repressão e à abertura dos arquivos oficiais existentes. Por sua vez, o "direito à memória" se referiria à inserção ou reinserção de alguns discursos no contexto social. ${ }^{2}$ Não aprofundaremos esta discussão neste trabalho.

Apesar do debate em torno da memória ter se difundido no Brasil recente, sempre haverá seu oposto, sua contradição inescapável: o esquecimento. Em $O$ processo, Kafka (2013, capítulo 07) narra o absurdo de um Tribunal que não esquece nada. $\mathrm{O}$ dever de esquecimento poderá contrapor o dever de memória. Existiria, por exemplo, o dever de esquecer o crime pelo qual o agressor já pagou ${ }^{3}$, quando a memória consistiria em violação, implicando uma espécie de bis in idem, ou o dever de esquecer o que nem a vítima quer lembrar (TODOROV, 2000, p. 25). Contudo, o primeiro caso suscita uma discussão - se o crime possui uma razão política e é cometido em uma conjuntura de repressão, a situação se altera. Como esquecer os crimes cometidos pelos nazistas punidos em Nuremberg? Ainda que punidos, estes crimes permanecem no imaginário coletivo. Neste caso, a memória pode ter um lugar, mas se abusaria dela para reavivar o ódio, como no alerta lançado por Tzvetan Todorov, mencionando a crueldade dos sérvios contra outros povos da ex-Iugoslávia, que teve como

2 Para aprofundamento desta perspectiva, ver o importante trabalho de Marcelo Torelly (2012. p. 270-271). 3 Sobre o assunto, o Conselho da Justiça Federal, na VI Jornada de Direito Civil, aprovou o seguinte enunciado:

"ENUNCIADO 531 - A tutela da dignidade da pessoa humana na sociedade da informação inclui o Direito ao esquecimento.

Artigo: 11 do Código Civil.

Justificativa: Os danos provocados pelas novas tecnologias de informação vêm-se acumulando nos dias atuais. O Direito ao esquecimento tem sua origem histórica no campo das condenações criminais. Surge como parcela importante do Direito do ex-detento à ressocialização. Não atribui a ninguém o direito de apagar fatos ou reescrever a própria história, mas apenas assegura a possibilidade de discutir o uso que é dado aos fatos pretéritos, mais especificamente o modo e a finalidade com que são lembrados.". Após isso o STJ aplicou o "Direito ao esquecimento" em dois casos, ambos relacionados ao programa "Linha direta Justiça" da TV Globo. No REsp. 1334097 a TV Globo foi condenada por danos morais, enquanto que no REsp. 1335153 apesar da aceitação da tese do "Direito ao esquecimento", entendeu-se que, no caso, não houve dano moral. 
uma de suas grandes justificações a memória de sofrimentos passados ${ }^{4}$. Todorov diz que o culto à memória nem sempre serve à justiça e, muitas vezes, é desfavorável para a própria memória (TODOROV, 2000, p. 56). $\mathrm{Na}$ Europa de hoje, a memória da Segunda Guerra mundial permanece viva, conservada por inúmeras comemorações, publicações e transmissões de rádio e televisão, mas a repetição do ritual de que não podemos esquecer não tem repercutido sobre os processos de limpeza étnica, racismos, torturas e execuções em massa que se produzem ao mesmo tempo (TODOROV, 2000, p. 58). Igual preocupação embala a luta de Cecília Coimbra (2008, p. 20), vítima da ditadura militar brasileira. Segundo ela, falar de memória e reparação seria também colocar em análises políticas de segurança pública que se fortalecem na contemporaneidade e se justificam em nome da guerra aos perigosos, produzindo a fascistização do cotidiano. Deve se considerar, igualmente, que no Brasil e em muitos outros lugares, a tortura e uma série de outras violações continuam sendo aplicadas em dependências policiais e carcerárias e em muitos estabelecimentos utilizados para a suposta reeducação de jovens infratores (COIMBRA, 2008, p. 23).

Por conta disto, duas ressalvas são fundamentais: primeiramente devemos ter cuidado, para que a memória não se transforme em ressentimento negativo e seja levantada para produzir o ódio; segundo, precisamos atentar para a distinção entre memória individual e memória coletiva, sendo esta construída por aquela (MATE, 2008. p. 157); além do fato de que a memória coletiva nem sempre é emancipadora, como a memória do medo na cidade do Rio de Janeiro, bem colocada por Vera Malaguti Batista (2010). Nestes casos será preciso interromper a memória.

Com estas ressalvas introduzimos o capítulo seguinte, que tratará da vítima como paradigma da memória.

\section{A vítima como paradigma}

4 Todorov diferencia a recuperação do passado do seu uso, afirmando que não há um automatismo vinculando os dois gestos. Para essa discussão, ver TODOROV, 2000. p. 27; MATE, 2006. p. 127; e ainda MATE, 2008. p. 173. 
Primeiramente é importante destacar que muitos coletivos, movimentos e pensadores têm buscado palavras diferentes para a ideia de vítima $^{5}$, na tentativa de sair de uma suposta negatividade e impotência do conceito. Outros termos são utilizados, tais como atingidos, oprimidos ou afetados. De fato, há um perigo e uma dificuldade na definição de vítima. Algumas vezes haverá uma certa confusão nestes papéis. Jean-Marie Gagnebin (2006. p. 56) menciona como um dos perigos da memória a identificação, por vezes patológica, de indivíduos aos papéis de vítima ou algoz, como se a busca de si tivesse que ser a repetição destes ${ }^{6}$. Por isso a importância, para Gagnebin, da ampliação do conceito de testemunha; de modo que aqueles que não são herdeiros de um massacre possam retomar a história e transmiti-la em palavras diferentes, para, assim, se livrarem deste círculo de fixação e identificação. A testemunha não seria somente aquela que viu com os próprios olhos, mas também quem ouviu o relato espantoso e insuportável e, no entanto, ficou até o final ${ }^{7}$. Como Primo Levi nos alerta, em breve as vítimas terão desaparecido e restarão apenas os ouvintes. $O s$ juízes ${ }^{8}$.

Para os objetivos deste trabalho se manterá a palavra vítima, por ser usada por Reyes Mate, filósofo que servirá como base teórica para este debate, apesar de que em certos momentos nas referências à Walter Benjamin aparecerá a figura do oprimido. Ressalte-se que nem a vítima em Mate tampouco o oprimido em Benjamin são categorias negativas. Veremos a seguir que o oprimido luta.

De acordo com Mate (2011b, p. 210-11), três pontos são fundamentais para entender a noção de vítima. Primeiro, que existem vítimas e vitimizadores. Segundo, vítima é quem sofre violência praticada por outra pessoa, sem nenhuma razão. Por isso a vítima é sempre inocente.

5 O paradigmático livro Brasil Nunca Mais já utilizava a palavra atingidos. O mesmo vale para o recente livro Atingidas: histórias de vida de mulheres na cidade olímpica. PACS. 2016.

6 Em Mate, vemos que pouco serviria uma história a partir dos vencidos, se esta for tão particular quanto a dos vencedores. O que importa é transcender vencidos e vencedores (MATE, 2011. p. 174).

$7 \mathrm{Em} \mathrm{Si} \mathrm{esto} \mathrm{es} \mathrm{un} \mathrm{hombre} \mathrm{Primo} \mathrm{Levi} \mathrm{conta} \mathrm{seu} \mathrm{pior} \mathrm{pesadelo:} \mathrm{está} \mathrm{novamente} \mathrm{em} \mathrm{casa} \mathrm{e} \mathrm{é} \mathrm{um} \mathrm{prazer}$ imenso, porém ao narrar o que lhe havia acontecido no campo, seus amigos não conseguem prestar atenção, e sua irmã vai embora. Não conseguem ouvir o relato estarrecedor (LEVI, 2002. p. 35).

8 Levi conta que certa vez uma jovem leitora lhe perguntou o que podemos fazer?, e ele respondeu os juízes são vocês. Mate questiona sobre que resposta podemos esperar de um leitor. Para ele apenas uma: a de manter viva, nas gerações seguintes, quando tiverem desaparecido as testemunhas, a vigência da injustiça passada. A Justiça não teria nada a ver com castigar o culpado (como quer o Direito), mas com a resposta à injustiça. Ver LEVI, 2002. p. 106; MATE, 2008. p. 169; e MATE, 2011. p. 165 (nota de rodapé). 
Terceiro, a vítima é significativa em si mesma. Ou seja, não há hierarquia entre vítimas, independente de suas posições ideológicas. Para Fernanda Telha (2015. p. 72), considera-se como vítima aquele indivíduo que experienciou um acontecimento injusto. Por isso, a Justiça a ser buscada após o fenômeno da injustiça se afasta da concepção da Justiça procedimental, uma vez que se vê como de fundamental importância - mais do que o castigo dos culpados, numa perspectiva de ajustiçamento - a invocação de que sejam tomadas medidas que reparem o mal causado à vítima em primeiro lugar.

\section{Memória e a responsabilidade pelo que não fizemos}

A centralidade da vítima é a chave da teoria de Reyes Mate, que interpreta o novo momento da memória após a segunda guerra mundial e as reflexões sobre o dever de memória, sendo um dos responsáveis por refazer a discussão em torno da experiência do franquismo e da transição espanhola baseada no esquecimento. Com forte influência de Walter Benjamin, o filósofo propõe uma virada hermenêutica que polemiza com autores como John Rawls e Jurgen Habermas, que produzem teorias baseadas no presente, em que o passado não é levado em consideração (MATE, 2006, p. 127; 2008, p. 169-170). Ao contrário, uma teoria que prioriza a memória tem em consideração as injustiças passadas, dando voz ${ }^{9}$ aos oprimidos, aos vencidos, aos injustiçados. Não seria possível, assim, produzir uma teoria da Justiça esquecendo as injustiças do passado, que, ao não serem sanadas, continuam sendo injustiças presentes. $O$ que vem primeiro não é o padrão de Justiça, mas sua violação, reconhecendo-se na experiência da injustiça o ponto de partida para a Justiça. Concede-se, portanto, uma centralidade às vítimas de injustiças.

\footnotetext{
9 Aqui há um sentido epistemológico. Não significa falar pelos outros, senão considerar o pensamento que foi esquecido ou apagado. Por exemplo, Mate elaborará uma teoria da Memória a partir dos pensadores judeus esquecidos da modernidade, dizendo que o pensamento existe, mas não é considerado. Nesse sentido damos voz aos esquecidos. Ver MATE, Reyes. Memoria de occidente. Actualidad de pensadores judíos olvidados. Rubí (Barcelona): Anthropos Editorial, 1997.
} 
A memória consistiria em fazer visível o invisível, o ponto de vista do oprimido; e sem memória da injustiça não há Justiça possível (MATE, 2008. p. 168). Isto nos leva a uma visão diferente da memória, relacionada a uma atividade hermenêutica, que não tem nada a ver, por exemplo, com ter decorado os nomes de todos os presidentes brasileiros. Mesmo porque não é possível contar a história exatamente como foi e nessa pretensão se esconde o mal mais terrível do século XIX (MATE, 2008, p. 164). Segundo Gagnebin (1982, p. 26), escrever a história dos vencidos exigirá a aquisição de conhecimentos que não constam nos livros da história oficial. Na tese seis sobre o conceito de história, Benjamin (1984, p. 224-225) nos lembra que articular o passado historicamente não significa conhecê-lo exatamente como ele foi, mas apoderar-se de uma lembrança tal como ela lampeja num instante de perigo ${ }^{10}$. O importante não são os fatos em si mesmos (como crê o "historicismo" criticado por Benjamin), senão o significado no aqui e agora (MATE, 2011b, p. 185).

Seria necessário olhar para o passado como um texto que nunca foi escrito e fazer visível o invisível. De que maneira? Mate (2011a, p. 160; 2008, p. 164-165) cita o exemplo de Allende no Chile, mas podemos falar de João Goulart (Jango) no Brasil. Ambos estão presentes através das suas ausências. A ditadura não foi a única realidade depois do golpe a Jango. Ela foi a realidade fática, mas, para compreender totalmente a realidade daquele tempo, inclusive para entender o vencedor, devemos levar em consideração o projeto que foi abortado abruptamente, percebendo a ausência dos que foram vencidos.

Sem essa ausência não entendemos bem a presença do vitorioso, ao mesmo tempo em que nos privamos de uma arma eficaz para a superação do presente. Essa ausência não é captável cientificamente. Sobrevive na memória dos perdedores

10 Gagnebin vê nessa afirmação uma recusa clara ao ideal de ciência histórica que Benjamin, pejorativamente, qualifica como historicista e burguesa. Uma ciência que pretende fornecer uma descrição mais exata e exaustiva possível do passado. Tal recusa se fundamenta em razões epistemológicas e éticopolíticas. GAGNEBIN, 2006, p. 40. 
e se ativa cada vez que se propõe a saída do terror dominante. (tradução nossa) ${ }^{11}$

Esta é uma das razões que levam Levi a dar tamanha importância ao testemunho. Em Os afogados e os sobreviventes (2004), ele conta que os SS se divertiam avisando cinicamente que não importava o desfecho daquela guerra, pois a guerra contra os detentos já estava ganha: ninguém sobraria para dar testemunho, as provas seriam destruídas e, ainda que alguma coisa restasse, as pessoas não dariam crédito. Com isso, o recordar, para Levi, significa ganhar uma batalha.

O sentido político deste ato de recordar pode ser resumido na famosa frase de Theodor Adorno: orientar o pensamento e a ação para que Auschwitz não volte a se repetir, que nada semelhante volte a ocorrer; ou, resumido por Mate (2008, p. 111-112): recordar para que a barbárie não se repita; ou seja, mais que um dever de recordação, a memória consiste em entender o significado da barbárie.

Desse modo, questionar os direitos negados no passado e afirmar a vigência do dano suportado pela vítima, significa também denunciar os vínculos existentes entre as injustiças passadas e as presentes. Como fica claro em Alberto Sucasas e José Antonio Zamora:

Considerar o desafio das vítimas exige reconhecer o significado das contas e reclamações de Justiça pendentes com o passado como condição para quebrar a lógica de dominação que segue produzindo vítimas destinadas a cair no poço do esquecimento. (tradução nossa) ${ }^{12}$

11 Sin esa ausencia no entendemos bien la presencia del ganador, al tiempo que nos privamos de un arma eficaz para la superacion del presente. Esa ausencia no es captable cientificamente. Sobrevive em la memoria de los perdedores y se activa cada vez que se plantea la salida del terror dominante. MATE, 2011, p. $186-87$.

12 Tener en cuenta la provocación de las victimas exige reconocer el significado de las cuentas pendientes con el passado y las reclamaciones de justicia pendiente como condición para quebrar la lógica de dominación que sigue produciendo victimas destinadas a caer en el pozo del olvido. SUCASAS \& ZAMORA. 2010. p. 11. 
Sem memória, as injustiças deixariam de ser injustiças e deixariam de existir; porque alguém dirá que o sofrimento dos inocentes é o preço a ser pago para que os outros vivam melhor e porque, sem memória que as atualize, as injustiças serão somente negatividade (MATE, 2006. p. 36). Desse modo, pensar a Memória deve ter como objetivo introduzir na Teoria da Justiça e na Teoria do Conhecimento o ponto de vista dos esquecidos, reordenando-as drasticamente e, indicando no terreno de hoje o espaço no qual o velho está conservado, para se afastar da ilusão historicista daqueles que fazem apenas o inventário dos achados (BENJAMIN, 1987, p. 239). Entretanto, o pensador da memória deve ir além. Não basta salvar, reparar ou lembrar o oprimido. É preciso continuar sua luta e realizar seus sonhos (LOWY, 2005, p. 53). Assim ensina Benjamin (1984. p. 223) na segunda tese sobre o conceito de história:

(...) O passado traz consigo um índice misterioso, que o impele à redenção. Pois não somos tocados por um sopro do ar que respiramos antes? Não existem, nas vozes que escutamos, ecos das vozes que emudeceram? Não têm as mulheres que cortejamos irmãs que elas não chegaram a conhecer? Se assim é, existe um encontro secreto, marcado entre as gerações precedentes e a nossa. Alguém na Terra está a nossa espera. Nesse caso, como a cada geração, foi-nos concedida uma frágil força messiânica para a qual o passado dirige um apelo. Esse apelo não pode ser rejeitado impunemente.

Cada caso de sofrimento e frustração deve ser compreendido em absoluto se opondo ao pensamento que vê a desgraça como algo natural. Contra essa naturalização, Benjamin fala de uma natureza messiânica, ou seja, a ordem profana fecundada com o sentido do sofrimento das vítimas. A vida é o lugar do conflito, da miséria e do fracasso, mas esse sofrimento não é o preço de nenhuma felicidade, senão uma exigência de Justiça. A chave para compreender essa existência justa seria levar a sério a significação teórica do sofrimento, buscando no mundo, em seus conflitos e aporias, o sentido da existência. 
Mate cita a primeira tese ${ }^{13}$. Nesta, Benjamin relaciona teologia e materialismo histórico, ou, para Mate, messianismo e tradição dos oprimidos. O que se toma disso é, do ponto de vista filosófico, uma concepção de Verdade como Memória, ou seja, partindo da experiência do sofrimento e, no que diz respeito à política, uma política como redenção (MATE, 2008, p. 202-203). O primeiro elemento dessa política como redenção é a vigência dos Direitos e, portanto, das esperanças insatisfeitas das vítimas. Independentemente do tempo transcorrido é preciso reconhecer as injustiças passadas. $O$ segundo componente é a responsabilidade das gerações posteriores sobre as anteriores, que se funda na relação histórica comum, da qual todos somos herdeiros. O terceiro elemento é a Interrupção. O Messias vem para interromper a história. O desenvolvimento não chega ao final (MATE, 2008, p. 204-206). A salvação consiste em interromper a lógica fatal da história, que vem produzindo tragédias e injustiças. É necessário, pois, acelerar o final para que outro mundo seja possível.

Logo, o apelo da geração passada não pode ser rejeitado porque o presente sobre o qual estamos assentados foi construído às custas dos que morreram à margem da história (indígenas, negros escravizados, judeus, comunistas, mulheres). Recusar o apelo do passado significaria garantir as bases que nos mantêm na lógica de injustiça e dominação. Existe, portanto, um continuum entre os vencedores de um lado e os vencidos de outro aqueles que uma vez dominam são herdeiros de todos os que dominaram até aquele momento (BENJAMIN, 1984, p. 225). Devido a isso não há um único documento de cultura que não seja também um documento de barbárie.

O materialista histórico deve então se afastar dessa transmissão e possuir empatia com o vencido. Ou nas palavras de Mate (2011a, p. 102): há uma continuidade entre os que lutaram no passado pela democracia e a democracia atual. Sem a memória dessas mortes jamais compreenderemos

13 “Conhecemos a história de um autômato construído de tal modo que podia responder a cada lance de um jogador de xadrez com um contralance, que lhe assegurava a vitória. Um fantoche vestido à turca, com um narguilé na boca, sentava-se diante do tabuleiro, colocado numa grande mesa. Um sistema de espelhos criava a ilusão de que a mesa era totalmente visível, em todos os seus pormenores. Na realidade, um anão corcunda se escondia nela, um mestre no xadrez, que dirigia com cordéis a mão do fantoche. Podemos imaginar uma contrapartida filosófica desse mecanismo. O fantoche chamado 'materialismo histórico' ganhará sempre. Ele pode enfrentar qualquer desafio, desde que tome a seu serviço a teologia. Hoje, ela é reconhecidamente pequena e feia e não ousa mostrar-se." (BENJAMIN, 1984. p. 222). 
nossa realidade. E mais, há um passado frustrado que ainda existe como potência e pode vir a ser presente se redimido do seu fracasso. Será necessário encontrar um passado sem conexão com o presente, para produzir uma realidade que não seja fruto das mesmas tradições. Do contrário, o inimigo continuará vencendo e nem os mortos estarão a salvo (BENJAMIN, 1984, p. 224-225). É disso que trata a tese dois, citada acima. Alguns herdam fortunas e outros infortúnios. Entre ambas as heranças existe uma relação histórica, que funda a responsabilidade (MATE, 2008. p. 206). Uma responsabilidade pelo que não fizemos.

\section{Por uma responsabilidade histórica}

Está claro que estamos diante de uma responsabilidade diferente do habitual, que vai além dos significados jurídicos ou sociais do termo. Mate busca desenvolver melhor essa ideia, apontando que em termos éticos ou filosóficos seria possível falar em responsabilidades históricas, coletivas ou políticas.

Algo para mim está claro: que eu não posso fugir do mal do mundo e que se é certo que são muitas as ações individualizadas que concorrem em um único ato histórico, a resposta deveria ser, pelo menos, coletiva ou política. (tradução nossa) ${ }^{14}$

Aqui já podemos notar a diferença entre a responsabilidade jurídica e a responsabilidade no âmbito moral. A responsabilidade jurídica diz respeito a imputar a alguém uma conduta danosa, forçando-o a sofrer uma pena ou reparar o dano. No âmbito moral existiria uma polissemia. Fala-se em responsabilidade pelo próximo, pelas gerações futuras, em

14 Algo sí me queda claro: que no me puedo desentender del mal del mundo y que si es certo que son muchas las acciones individualizadas que concurren em um único acto histórico, la respuesta debería ser, al menos, colectiva o política. (MATE, 1997, p. 264). 
responsabilidade histórica ou responsabilidade política. A identificação do autor ou sujeito do ato pode ser o ponto de partida, mas nem todo o problema de responsabilidade se reduz a isso. Filosoficamente, a ideia de responsabilidade alcançaria muito mais do que nossa vontade ou intenção podem saber. Há um afastamento importante da noção jurídica de Responsabilidade.

Rafael Vieira (2016, p. 42) nos mostra que, em Benjamin, ocorre uma separação entre os mundos da Ética e da Justiça e o mundo do Direito, neste último, onde se opera no vivente uma marcação de culpa inderrogável. Culpa, do alemão shuld, também significando dívida, sendo que os instrumentos da reincidência e dos antecedentes criminais são demonstrações precisas da culpa como dívida que jamais pode ser retirada (VIEIRA, 2016, p. 50). Uma vez culpado, sempre endividado - o Direito não condena a punição, mas a culpa, dirá Benjamin (2011, p. 94 Apud VIEIRA, 2016, p. 102). A vida antes é condenada, para depois tornar-se punível. A morte social provocada pela culpa é outro elemento a expor a dívida que nunca se paga. Uma vez condenado (ou mesmo acusado), jamais se retorna ao estado anterior. A culpa marca para sempre e conduz a morte social. Nesse sentido, podemos afirmar que toda prisão é perpétua e toda pena é de morte (mas algumas são mais perpétuas e mortais que as outras). O juiz terá sempre o poder (assombroso poder) de determinar o destino do réu.

O conceito jurídico de culpa (também religioso e moral) aparece como pressuposto do sistema estatal de punição, expressando um modelo social fundado na vingança/retribuição. Com isso, ocorre uma captura da dimensão ética de Justiça, reduzindo-a a um sentido jurídico. Neste modelo, inocência e perdão são irrealizáveis (VIEIRA, 2016, 97-102). Mesmo porque o Direito não se preocupa senão com sua própria manutenção: o interesse do Direito em monopolizar o poder diante do indivíduo não se explica pela intenção de garantir os fins jurídicos, mas de garantir o próprio Direito (BENJAMIN, p. 62 Apud VIEIRA, p. 74).

Devido a isso alguns autores tentarão diferenciar Culpa e Responsabilidade. Para Carmelo Garcia, a diferenciação das duas categorias é importante para pensá-las em termos pessoais e coletivos e pensar as possibilidades de perdão, redenção, restituição. A culpabilidade é a consciência da culpa, do pecado, do delito cometido ou permitido. A culpa não seria uma característica fundamental humana, mas uma invenção 
que diminuiu a responsabilidade e freou a liberdade, criando medos e perdões mágicos (GARCIA, 2007, p.349).

\begin{abstract}
Penso e mantenho que ajudar a emancipar-se da culpa e assumir responsabilidades (...) deveria ser a chave, a regra básica para decifrar a realidade ou a mitologia em toda boa hermenêutica do acervo chamado "cristão" ou bíblico (também em outros universos simbólicos ainda que não sejam de natureza mítica ou religiosa). (tradução nossa). ${ }^{15}$
\end{abstract}

A responsabilidade seria mais objetiva - a obrigação coletiva de reconhecer o fato e a implicação que como sujeito histórico tivemos ou temos para com ele, de modo a reparar o dano e o sofrimento. Uma obrigação moral de dar satisfação, restituir, reparar e indenizar as vítimas e seus herdeiros. Existiria também uma responsabilidade positiva de seguir a obra boa e terminá-la (GARCIA, 2007, p.350).

Manuel Cruz (1999. p. 12) aponta a crescente importância que a categoria responsabilidade vem ganhando no mundo. Podemos encontrá-la diariamente em diversos contextos: fazendo referência à atitudes que se esperam dos políticos, passando por problemas educacionais, familiares e até esportivos, sem esquecer o Papa, que, eventualmente, fala da responsabilidade da igreja por episódios do passado.

Essa quase onipresença do conceito não garante que conheçamos seu significado, tornando a tarefa do intérprete cada vez mais difícil. Segundo Cruz, na política, isso pode ser perceptível mais facilmente:

Setores conservadores estão se servindo da noção de responsabilidade individual com (pouco) mascarado propósito de esvaziar de conteúdo a noção de responsabilidade coletiva, que lhes incomoda na medida em que implica custosos

15 pienso y mantengo que ayudar a emanciparse de la culpa y assumir responsabilidades.. deberia ser la clave, la regla básica para descifrar la realidade o la mitologia em toda buena hermenêutica del acervo llamado "cristiano" o bíblico (también em otros universos simbólicos aunque no sean de naturaliza mítica, mágica o religiosa...). (GARCIA, 2007, p.349-350). 
compromissos de solidariedade com os segmentos sociais mais desfavorecidos ${ }^{16}$.

Assim, não tratam da responsabilidade da sociedade para com os desempregados, os enfermos, os refugiados; mas de suas responsabilidades individuais - dos desempregados na obtenção de trabalho, dos enfermos no uso de seus medicamentos e assim sucessivamente. Outra dificuldade é a relação entre culpa e responsabilidade. A culpa está negativada por toda tradição judaico-cristã, enquanto que a responsabilidade pode nos oferecer elementos positivos. Pensar o responsável como aquele que assume a reparação dos danos causados e generalizando esse mecanismo, nos dirigimos a uma mudança de atitude coletiva, que pode ser resumida assim: a partir de certo momento do desenvolvimento das sociedades modernas, se assume que, independentemente de quem possa ser o culpado, todo mal deve ser reparado (CRUZ, 1999. p. 13).

Entretanto, a tendência pela responsabilidade coletiva não gera a proliferação de pessoas dispostas a assumir culpas, senão a escassez de pessoas que aceitem a mínima responsabilidade. Pior que a autoculpabilização é a tentação da inocência (CRUZ, 1999. p. 14). Ser (ou parecer ser) um homem bom, honesto, estar livre de toda reprovação, se converte em uma fantasia dominante de nossa sociedade (CRUZ, 1999. p. 15). Fantasia impossível pois

Se a responsabilidade é, fundamentalmente, pelos próprios atos, somente consegue estar a salvo das reclamações alheias aquele que nunca erra, que não termina nenhum ato ou, a mais

16 Sectores conservadores se están sierviendo de la noción de responsabilidad individual con el poco enmascarado propósito de vaciar de contenido la noción de responsabilidad colectiva, que a ellos les incomoda en la medida en que implica costosos compromisos de solidariedad con los segmentos sociales más desfavorecidos. (CRUZ, 1999. p. 13) 
inaceitável das hipóteses, aquele cujos atos, como das crianças e dos loucos, não são levados em conta por ninguém ${ }^{17}$.

Ninguém está a salvo das reclamações alheias ao mesmo tempo em que a responsabilidade, fundamentalmente, diz respeito aos atos próprios e exige um outro (alguém que reclame resposta). Nossas ações mudam a vida dos outros, seus sentimentos, impulsos, ódios e simpatias e, se podemos influenciar os demais, nada é gratuito e estamos cheios de responsabilidade, ao mesmo tempo em que a ação não pertence unicamente ao agente. A vítima reclama responsabilidade ao mesmo tempo em que deve assumir as suas (CRUZ, 1999. p. 16-18). Estamos diante de uma coletivização individualizante. Não somos culpados por tudo, mas sempre seremos responsáveis por algo.

De fato, Cruz introduz uma responsabilidade com ambiguidade particular, individual e genérica. Uma responsabilidade pelo que nos vai acontecendo, uma responsabilidade de caminhada, se afastando do sujeito global e indeterminado; no limite, uma responsabilidade pela própria vida, que na prática concreta do indivíduo pode ser resumida: somos responsables ante quienes nos necesiten. (CRUZ, 1999, p.22-23)

Aprofundando a noção de responsabilidade, um conceito difícil de fundamentar porém fundamental, Mate (2011b. p. 246) dirá que trata-se de tomar em conta o outro, inaugurando uma nova relação com os limites que impõem o tempo e o espaço. A responsabilidade jurídica, portanto, ao se preocupar com as vítimas e agressores do aqui e agora, deixa de fora a reparação às vítimas do passado. Existiria uma responsabilidade que expandisse as noções de tempo e espaço? Na filosofia moral kantiana, desenvolve o filósofo espanhol, o importante será a atribuição de uma ação reprovável a um sujeito que precisa responder. Somos responsáveis apenas pelo que fizemos. Que não nos peçam conta do que não fizemos ${ }^{18}$. Ao contrário, busca-se uma responsabilidade pelo que não fizemos.

17 si la responsabilidad es en lo fundamental por los próprios actos, solo consigue estar a salvo de las reclamaciones ajenas aquel que nunca yerra, el que no lleva a cabo acto alguno o, la más inaceptable de las hipótesis, aquel cuyos actos, como los del niño o el loco, no son tomados en cuenta por nadie. (CRUZ, 1999 , p. 15)

18 Todavia, mesmo essa liberdade não pode esgotar-se apenas no ato, porque cada ato põe em marcha uma cadeia de acontecimentos podendo prolongar-se no tempo. (MATE, 2011. p. 247-248). 
Uma responsabilidade histórica é convocada pelo sofrimento e pela herança comum que a injustiça nos legou (MATE, 2011b. p. 258). Em Levinas $^{19}$, nos tornamos sujeitos humanos graças ao outro, na medida em que somos responsáveis pelo outro (MATE, 2011, p. 258). Essa responsabilidade não tem diante de si um outro genérico, mas alguém que sofreu um dano causado pelo homem. E a Memória nos coloca a demanda do Outro: "com a presença do outro se inaugura o tempo, pois permite à existência que haja algo mais que o dado. Permite que o presente tenha futuro" (tradução nossa) ${ }^{20} \mathrm{O}$ olhar, através do sofrimento do outro, possui consequências teóricas e práticas. Uma responsabilidade com o tempo busca no passado algo que nos diga mais sobre o presente; um pequeno fato, por exemplo, que a primeira igreja do Brasil foi erguida em comemoração a uma vitória dos portugueses sobre povos indígenas ${ }^{21}$, nos ajuda a destruir a fortaleza do fático, do que está dado; e assim compreender melhor as violência do presente contra esses povos.

Assumir uma responsabilidade deste tipo significaria reviver, revitalizar a memória histórica, sua razão, as culturas vivas, a consciência dos povos, a validade de suas tradições (GARCIA, 2007, p.335); projetando material e moralmente para um novo futuro possível e melhor, compreendendo o esquecimento como negação do que somos. A pergunta que importa é: o que aconteceu no tempo e nos diferentes espaços e setores, até que desembocamos em uma realidade como a atual, com suas imensas irracionalidades? Para responder a essa pergunta será necessário analisar as causalidades histórico-estruturais, as tramas causais dos processos que produzem e reproduzem os fatos em relação com os sujeitos que os sofrem

19 Em Levinas há uma responsabilidade como alteridade: “eu sou responsável por outrem sem esperar a recíproca (...) o eu sempre tem uma responsabilidade a mais que todos os outros." LEVINAS, Emmanuel. Ética e Infinito APUD POIRIÉ, François. Emmanuel Levinas: ensaio e entrevistas. 2007. P. 39. "Mas é sempre a partir do rosto, a partir da responsabilidade por outrem, que aparece a Justiça". LEVINAS, Emmanuel. Entre nós: Ensaios sobre alteridade. 2005. p. 144. "Ouvir a miséria que clama por Justiça não consiste em representar-se uma imagem, mas em colocar-se como responsável, ao mesmo tempo como mais e como menos do que os ser que se apresenta no rosto. Menos, porque o rosto me chama as minhas obrigações e me julga." LEVINAS, Emmanuel. Totalidade e Infinito. 2000. p. 193. "Entendo a responsabilidade como responsabilidade por outrem, portanto, como responsabilidade por aquilo que não fui eu que fiz, ou não me diz respeito". LEVINAS, Emmanuel. Ética e infinito. 1982. p. 87-88.

20 con la presencia del otro se inaugura el tiempo, pues permite a la existencia que haya algo más que lo dado. Permite que el presente tenga futuro (MATE, 2011, p. 206).

21 Instituto do Patrimônio Histórico e Artístico Nacional (IPHAN). IGARASSU (PE). Disponível em: <http://portal.iphan.gov.br/pagina/detalhes/350>. Consultado em: 26/01/2018. 
- as vítimas - mais do que em relação aos que dirigem e executam os fatos (GARCIA, 2007, p.336). Tais questões também devem se dirigir aos agentes históricos de hoje, para além de criar tribunais penais internacionais, o que fazer com a responsabilidade num momento onde evitavelmente são assassinadas mais pessoas que no holocausto? (GARCIA, 2007, p.337)

Caberia uma responsabilidade dos netos pelo que fizeram seus avôs? $\mathrm{E}$ os atos que ocorrem ao nosso redor, dos quais somos apenas espectadores? Aqui, seria o caso de dividir os atos em contemporâneos e passados. Quanto aos atos contemporâneos há extensa bibliografia sobre a conduta dos alemães durante o período nazista. Mate se utiliza de Karl Jaspers, que no livro A questão da culpa se pergunta sobre o alcance da responsabilidade de todos os alemães pelos fatos do nazismo. Haveria três tipos de culpa (ou responsabilidade) ${ }^{22}$ : 1) moral, porque há condutas não previstas na lei que seriam objetos de responsabilidade. A indiferença, por exemplo; 2) política, dos cidadãos que eram membros de um Estado criminoso, inclusive dos descendentes; 3) metafísica, uma responsabilidade universal pelos desastres do mundo criados pela ação humana. A culpa metafísica teria um nível maior de exigência. Uma solidariedade da espécie contra o sofrimento, uma responsabilidade pelo que ocorre ao nosso redor (MATE, 2011b, p. 249-250). A responsabilidade com o passado seria diferente e deve cumprir dois requisitos: que as injustiças do passado sigam vigentes e que haja uma relação entre o passado injusto e nosso presente (MATE, 2011b, p. 250).

Responsabilidade é um conceito muito usado, porém escorregadiço, está no Direito e na Moral. No Direito significa pôr na conta de alguém uma ação condenável, referida à obrigação ou proibição de fazer algo. É a figura da imputatio. Mate (2007, p. 354-355) apresenta algumas críticas a esse modelo de responsabilidade. Primeiro, que a ideia de assumir responsabilidade está contaminando todas as condutas sociais, no sentido indenizatório. Responsabilizar-se significa cada vez mais indenizar materialmente. Segundo, a reparação material dos presentes deixa fora as injustiças do passado. Esse modelo de responsabilidade não lida com o

22 Shuld, literalmente culpa é traduzido como responsabilidade por Mate, porque atualmente teríamos claro que a culpas são individuais e as responsabilidades podem ser coletivas. 
problema das vítimas da história. Terceiro: sem um sujeito moral se torna difícil analisar outros aspectos que não se resolvem com a indenização.

No âmbito da filosofia moral aparece Kant, que fala na atribuição a um sujeito de uma ação reprovável da qual precisa responder. Tal atribuição é o juízo mediante o qual alguém é considerado causa livre de uma ação. Assim, somos responsáveis somente pelos nossos atos, derivados de uma ação livre. Mate (2007, p. 355-356) dirá que uma ação reprovável pode ser vista sob dois pontos de vista: 1) Se atravesso o sinal vermelho violo a lei e, portanto, sou merecedor de sanção; 2) Se atravesso o sinal vermelho e atropelo um homem cujo de seu salário sobrevive uma família e, depois, o filho em dificuldades financeiras encontra o caminho do crime, significa que a responsabilidade não se esgota no ato. Há uma cadeia de acontecimentos.

Essa dupla dimensão explica duas éticas da responsabilidade. Uma hegeliana, preocupada com as consequências (da qual Hans Jonas seria o último episódio), e uma kantiana, centrada na violação da lei (no caso a lei moral) (MATE, 2007, p. 356). As duas formas de responsabilidade são fundamentadas na liberdade e no que fizemos. Essa é a forma de pensar moderna. Todavia, aqui buscamos uma responsabilidade que olhe para trás.

Uma questão importante acerca da ideia de responsabilidade histórica diz respeito aos sujeitos dessa responsabilidade. Carmelo Garcia se debruça sobre esse tema. Para este pensador, a responsabilidade é própria da condição humana, que racional e livremente assume a autoria dos atos e suas repercussões em todos os efeitos, diretos ou induzidos, até as últimas consequências (tradução nossa) (GARCIA, 2007, p.333). Ou, em outras palavras, o cumprimento livre do dever para com o outro, no processo de construção da humanidade futura.

Entretanto, se existe responsabilidade histórica, deve existir um sujeito para se responsabilizar, o que coloca a questão sobre a própria existência de um sujeito histórico. Supondo que esse sujeito exista, haveríamos de descobri-lo e, mesmo encontrando-o, o mais importante seria que ele mesmo se descobrisse enquanto sujeito histórico responsável, senão de pouco valerá afirmar uma responsabilidade (GARCIA, 2007, p.335).

Sobre a complexidade na definição de sujeito histórico, Garcia (2007, p. 339) vai assinalar que é preciso ir além do indivíduo particular, que por si só não chega a acumular importância no tempo e espaço, nem possui dimensão - em qualidade e quantidade - suficiente. Isso significa 
que, no momento de medir a repercussão de um presumido sujeito histórico, teremos que situá-lo em alguma estrutura que o projete historicamente. Essa reflexão nos põe a pensar sobre um sujeito histórico coletivo, institucional, regulado, que ainda hoje continua e transmite/constrói memória em conexão com os mesmos sujeitos de cinco séculos atrás, em uma linha que hoje poderia ser continuada (GARCIA, 2007, p. 341).

A responsabilidade histórica tem relação direta com o sujeito responsável ou capaz de responsabilidade, que para além da pessoa individual, o sujeito deve possuir razão histórica ou ser sujeito historicamente consciente, que, por sua forma de viver, tenha uma natureza histórica e duradoura. Que tenham estruturas que transcendam o pessoal e o temporal (GARCIA, 2007, p. 346-347). Falando do caso latino-americano, Garcia (2007. p. 344-345) cita possíveis sujeitos históricos: os povos e sua memória histórica; as culturas e tradições; os Estado-nação violentadores; e a Igreja Católica. Os sujeitos violentadores deveriam tomar consciência do seu papel na América Latina desde o início e assumir as responsabilidades até as últimas consequências: pedindo perdão pela falta de pedido de perdão; restituindo o roubado e destruído e suas consequências; restabelecendo o futuro possível e a possibilidade de as vítimas recuperarem o protagonismo e a independência.

No caso da ditadura militar brasileira há sujeitos históricos que podem ser determinados, cujas responsabilidades vão além da atribuição pessoal de fatos - são responsabilidades políticas, coletivas, históricas. Talvez o mais emblemático deles, as organizações Globo, apoiadora do regime, pediu desculpas em 2013 após ser objeto de críticas contundentes e recorrentes nas grandes manifestações que tomaram o Brasil. Em editorial publicado n'O Globo ${ }^{23}$ afirmou que "Desde as manifestações de junho, um coro voltou às ruas: 'A verdade é dura, a Globo apoiou a ditadura'. De fato, trata-se de uma verdade, e, também de fato, de uma verdade dura", para concluir que à luz da história, seu apoio à ditadura havia sido um equívoco.

23 O GLOBO. Apoio editorial ao golpe de 1964 foi um erro. 31 de agosto de 2013. Disponível em <https://oglobo.globo.com/brasil/apoio-editorial-ao-golpe-de-64-foi-um-erro-9771604>. Último acesso em: 09 de setembro de 2019. 
O relatório final da Comissão Nacional da Verdade ${ }^{24}$ aponta mais de 80 empresas colaboradores da ditadura brasileira, envolvidas em espionagem e delação de seus funcionários. Dentre os casos mais conhecidos está o da Wolkswagen, em que consta informe sobre o expresidente e ex-líder sindical Luiz Inácio Lula da Silva. Sobre a Wolkswagen, em artigo recente ${ }^{25}$, Antoine Acker fala sobre sua responsabilidade histórica no Brasil de Bolsonaro, lembrando a participação da empresa no nazismo e na ditadura militar brasileira e repercutindo manifestações de alguns de seus diretores animados com a chegada ao poder da extrema-direita. Na Alemanha a VW participou de atividades de reconhecimento de sua contribuição ao regime, em parte como forma de limpar sua imagem, mas que implicou admissão de sua responsabilidade histórica, tal qual as organizações Globo no Brasil.

Ainda sobre o relatório da Comissão Nacional da Verdade, em alguns textos há manifesta menção a formas não individualizadas de responsabilidade, como quando fala das responsabilidades políticoinstitucional dos diversos órgãos que participaram das estruturas de repressão (Cap. 16), ou das responsabilidades de países como Inglaterra e Estados Unidos da América. Existe, assim, uma compreensão de que a responsabilidade não se esgota no ato individual, que há práticas coletivas, institucionais, políticas, que concorrem para um determinado evento histórico e que demandam responsabilidades.

\section{Conclusão}

Este trabalho procurou colocar a questão sobre como fazer justiça frente à injustiça do passado. Nos modelos tradicionais de justiça é perceptível a centralidade da responsabilidade individual. Buscamos compreender como a ideia de responsabilidade pode extrapolar esse

24 Disponível em: < http://cnv.memoriasreveladas.gov.br/>.

25 A responsabilidade histórica da Volkswagen no Brasil de Bolsonaro. Disponível em: < https://www.cartacapital.com.br/opiniao/a-responsabilidade-historica-da-volkswagen-no-brasil-debolsonaro/amp/>. 
modelo, trazendo o debate sobre responsabilidade histórica. Uma responsabilidade frente às injustiças do passado, que ao não serem respondidas, seguem sendo injustiças do presente repercutindo na realidade. Usamos a ideia da responsabilidade pelo que não fizemos em contraponto à responsabilidade como imputação individual, reivindicando uma responsabilidade histórica, pelo que fizeram - ou não fizeram - nossos antepassados. Reyes Mate e Carmelo Garcia a tratam desde a perspectiva da Memória. Uma Memória compromissada com os vencidos da História, os invisíveis. Em termos benjaminianos, haveria a história oficial dos vencedores, sendo a Memória a capacidade hermenêutica de fazer visível o invisível.

Uma resposta à injustiça não significa a resolução ou superação do conflito. A própria ideia de superação histórica é questionável. Viramos uma página, mas logo retornamos a ela outra vez. Sobre lidar com a injustiça do passado, a responsabilidade histórica nos impõe reparar o que pode ser reparado e lembrar o que não pode ser desfeito, com os requisitos de que as injustiças estejam ainda vigentes e que haja um vínculo entre passado e o presente.

$\mathrm{Na}$ maioria dos casos de violências históricas, não é possível desfazer o ocorrido, a página pode ser virada, lida e relida, mas nunca borrada. O que resta é a memória, cada vez mais debilitada na medida em que as testemunhas vão desaparecendo. Primo Levi, respondendo a uma pergunta sobre o que nos caberia fazer a respeito de Auschwitz, disse que deveríamos levar a história adiante, quando as testemunhas tivessem desaparecido. Como fazer Justiça aos seres humanos escravizados, se os algozes não estão mais presentes para receberem uma punição? Podemos dizer que há uma responsabilidade um pouco maior do que simplesmente reproduzir o relato histórico, ou castigar o culpado. Outra vez, em termos benjaminianos, seria o caso de realizar os vencidos. Seguir seus sonhos, seus pensamentos de um mundo bom, ou de uma humanidade redimida. Nos termos colocados por Carmelo Garcia, seguir a obra bem-feita. O mundo não é feito apenas de infortúnios a lamentar eternamente. Há sempre exemplos históricos a seguir e a responsabilidade histórica teria um viés positivo.

A abordagem de Carmelo Garcia é interessante. Uma tentativa de pensar os sujeitos de uma responsabilidade histórica. Apesar da dificuldade em determinar sujeitos coletivos, lançamos algumas bases importantes. Alguns sujeitos das violências seguem existindo: o Estado espanhol e 
português, a Igreja Católica no caso da colonização. Na ditadura brasileira, as empresas que derem suporte ao regime, meios de comunicação de massa, instituições e órgãos do Estado. A estes não parece haver dificuldade em atribuir uma responsabilidade histórica, que é diferente da retórica da dívida histórica que nunca se paga - mas serve como escusa nos debates contemporâneos sobre Memória e violência. É fácil reconhecer uma dívida que não se pode quitar. Um pouco mais difícil seria ver, na crise imigratória europeia e nas fronteiras criadas pelos homens, mais do que uma questão de $a z a r,{ }^{26}$ ou mesmo na conjuntura de ascensão do autoritarismo brasileiro as responsabilidades pela falta de memória da ditadura.

A principal tarefa da Memória seria encontrar os vínculos entre passado e presente. Compreender melhor a nossa realidade a partir do passado; assim, não garantiremos, mas contribuiremos para a não-repetição de violências. A responsabilidade das gerações posteriores com as anteriores existe porque somos herdeiros de um passado comum. Um passado, construído às custas dos que morreram à margem da história, reivindica uma responsabilidade como interrupção da lógica histórica de injustiça e dominação, que não cansa de produzir tragédias e injustiças. Uma Memória que atualize as violências do capitalismo, por exemplo - as expropriações originárias, colonizações e escravizações. Uma memória que, em sua relação com a vida, considere o tempo para rever o passado e desver o presente, incluindo o Outro na realidade. Precisamente o Outro que fora posto de lado.

A Memória deve servir para compreendermos algo mais sobre o presente, recolhendo pela rua os insólitos, os dejetos. Assim como Manoel de Barros desve $\hat{e}^{27}$ o mundo e as coisas, conferindo-lhes novos sentidos e se importa com as desimportâncias, Benjamin havia dito que, para compreender algo em sua forma verdadeira, devemos esquecer tudo o que aprendemos sobre aquilo. Deixar de ver (tal qual aquilo se apresenta), que não é o mesmo que perder de vista.

27 BARROS, Manoel de. Menino do Mato. In: BARROS, Manoel de. Poesia completa. 2010. p. 447-466. Trabalhei melhor esse tema em um ensaio com (suprimido para assegurar avaliação cega). AUTOR. 2016. 


\section{Referências}

ARAMAYO, Roberto. Los confines éticos de la responsabilidad. IN: CRUZ, Manuel \& ARAMAYO, Roberto. El reparto de la acción. Ensayos en torno a la responsabilidade. Madrid, Editorial Trotta. 1999.

BATISTA, Vera Malaguti. Memória e medo na cidade do Rio de Janeiro. In: $O$ olho da história, n. 14. Salvador, 2010.

BENJAMIN, Walter. Magia e Técnica, Arte e Política. Obras Escolhidas I. São Paulo: Brasiliense, 1984.

BENJAMIN, Walter. Rua de mão única. Obras Escolhidas II. São Paulo: Brasiliense. 1987.

COIMBRA, Cecília. Reparação e memória. Cadernos AEL, v.13, n.24/25, 2008.

CRUZ, Manuel. Acerca de la necesidad de ser responsable. IN: CRUZ, Manuel \& ARAMAYO, Roberto. El reparto de la acción. Ensayos en torno a la responsabilidade. Madrid, Editorial Trotta. 1999.

DIMOULIS, Dimitri. Justiça de Transição e função anistiante no Brasil. Hipostasiações indevidas e caminhos de responsabilização. In: DIMOULIS, Dimitri. et al. Justiça de Transição no Brasil: Direito, Responsabilidade e Verdade. São Paulo: Saraiva, 2010.

DIMOULIS, Dimitri \& SABADELL, Ana Lucia; Anistia: a política além da justiça e da verdade. Acervo - Revista do Arquivo Nacional, v. 24, n. 1, p. 79-102. Disponível em: http://hdl.handle.net/20.500.11959/brapci/42892. Acesso em: 10 set. 2019.

GAGNEBIN, Jeanne-Marie. Cacos da História. São Paulo: Brasiliense, 1982.

GAGNEBIN, Jeanne-Marie. Lembrar Escrever Esquecer. São Paulo: Editora H34, 2006.

GARAPON, Antoine. Crimes que não se podem punir nem perdoar. Lisboa: Piaget, 2004.

GARCIA, Carmelo. Sujetos de la responsabilidad histórica. In: MATE, Reyes (ed.) Responsabilidad histórica. Preguntas del nuevo al viejo mundo. Anthropos 2007. 
JUSTINO, D. Uma responsabilidade pelo que não fizemos? A memória como fundamento...

GUNTHER, Klaus. Teoria da responsabilidade no Estado democrático de Direito. Flavia Portella Puschel e Marta Rodriguez de Assis (Org). São Paulo, Saraiva. 2009.

KAFKA, Franz. O processo. Tradução de Marcelo Backes. Porto Alegre: L\&PM, 2013.

LEVI, Primo. Os afogados e os sobreviventes: os delitos, os castigos, as penas, as impunidades. São Paulo: Paz e Terra, 2004.

LEVI, Primo. Si esto es un hombre. Barcelona: Muchnik Editores, 2002.

LOWY, Michael. Walter Benjamin: aviso de incêndio: uma leitura das teses "Sobre o conceito de história". São Paulo: Boitempo, 2005.

MATE, Reyes. Contra lo politicamente correcto: política, memoria, justicia. Buenos Aires: Altemira, 2006.

MATE, Reyes. ¿Existe una responsabilidad histórica?. Claves de lá razón práctica 168. 2006.

MATE, Reyes. La herencia del olvido. Ensaios en torno de la razón compassiva. Madrid: Errata Naturae Editores, 2008.

MATE, Reyes. La razón de los vencidos (2 $2^{\mathrm{a}}$ edicion). Rubí (Barcelona): Anthropos Editorial, 2008.

MATE, Reyes. Meia-noite na história: comentário às teses de Walter Benjamin "Sobre o conceito de história". São Leopoldo, RS: Ed. UNISINOS, 2011a.

MATE, Reyes. Memoria de occidente. Actualidad de pensadores judios olvidados. Rubí (Barcelona): Anthropos Editorial, 1997.

MATE, Reyes (ed.). Nuevas teologías políticas: Pablo de Tarso en la construccíon de Occidente. Rubí (Barcelona): Anthropos Editorial, 2006.

MATE, Reyes. Tratado de Injustiça. Rubí (Barcelona): Anthropos Editorial, 2011b.

SUCASAS, Alberto \& ZAMORA, José A (Ed.). Memoria - Política - Justicia en diálogo con Reyes Mate. Madrid: Editorial Trotta, 2010.

TELHA, Fernanda. Reyes Mate e a Justiça das vítimas: uma perspectiva anamnética. Dissertação de mestrado. 2015.

TODOROV, Tzvetan. Los abusos de la memoria. Barcelona: Paidós, 2000. 
TORELLY, Marcelo D. Justiça de Transição e Estado Constitucional de Direito: perspectiva teórico-comparativa e análise do caso brasileiro. Belo Horizonte: Fórum. 2012.

VIEIRA, Rafael Barros. Walter Benjamin: O Direito, a política e a ascensão e colapso da República de Weimar. Tese de Doutorado (PUC-Rio). 2016.

RECEBIDO EM: 10/09/2019 APROVADO EM: 29/09/2019 